\title{
Casos de Implantação da QS 9000 em Empresas no Brasil
}

\author{
João Carlos Soalheiro Gonzalez, MSc \\ Wabco Freios - Brasil, Rodovia Anhanguera, km 106, 13001-970, Sumaré, SP \\ E-mail: joao-carlos.gonzalez@wabco-auto.com \\ Paulo Augusto Cauchick Miguel, PhD \\ Núcleo de Cestão da Qualidade \& Metrologia, Faculdade de Engenharia Mecânica e de Produção, Universidade Metodista de Piracicaba - \\ UNIMEP, Rodovia SP 306, km 1, 13450-000 Santa Bárbara d'Oeste, SP. \\ E-mail: pamiguel@unimep.br
}

\begin{abstract}
Devido as limitações da série ISO 9000, segmentos industriais específicos vêm desenvolvendo requisitos normativos específicos para seus fornecedores, com destaque para a cadeia de fornecimento do setor automotivo. Uma dessas iniciativas é o lançamento, em 1994, da QS 9000, que reune requisitos normativos de fornecedores da Ford, Chrysler e General Motors em todo o mundo. Esse trabalho apresenta os resultados da implantação da QS 9000 em uma empresa fabricante de freios automotivos, além de descrever seu desenvolvimento e conteúdo e destacar outros resultados de implantação extraídos da literatura.
\end{abstract}

Palavras-chave: QS 9000, Sistema da Qualidade, Certificação, Gestão da Qualidade

Due to the limitations of ISO 9000 series, some industrial sectors have developed quality standards requirements specifically to their suppliers. One of these sectors is the automotive. Among these initiatives there is the launching of QS 9000 in 1994, which congregates standard requirements for the suppliers of Ford, Chrysler e General Motors all over the world. This paper presents the results of QS 9000 implementation in a company, which produces brake systems. It also describes the development of QS 9000 and highlights other cases of implementation from the literature.

Keywords: QS 9000, Quality System, Certification, Quality Management.

\section{INTRODUÇÃO}

As normas de garantia da qualidade têm evoluído de forma significativa nos últimos anos. Enquanto que a série ISO 9000, cuja primeira edição foi lançada em 1987, revisada em 1994, e com nova edição que vigora a partir do final do ano 2000, segmentos industriais específicos têm lançado requisitos próprios para seus sistemas da qualidade. Dentre esses segmentos, destacam-se iniciativas do setor de telecomunicações (TL 9000), aeronáutico (AS 9000), e indústria automotiva (QS 9000). Essas iniciativas surgm em função de limitações existentes nos requisitos normativos da série ISO 9000. No caso do segmento automotivo americano, as três maiores montadoras Ford, Chrysler e GM ("the big three"), lançam a QS $9000 \mathrm{em} \mathrm{1994,}$ atualmente na sua terceira edição (1998) que vigor desde 1999. Existem atualmente, mais de 16.500 certificados emitidos em todo o mundo até agosto de 2000, com a previsão de atingir a marca de 40 mil cerificados de fornecedores da primeira e segunda linha da cadeia de fornecimento global dessas três grandes montadoras. A Figura 1 mostra o crescimento na certificação no mundo desde maio de 1998, registrados pela ASQ (American Society for Quality) nos EUA, e acompanhado pelos autores desse trabalho.

No Brasil, a busca da certificação pela QS 9000 é intensa, mobilizando um grande número de empresas de autopeças fornecedoras, no mercado interno ou externo, para as três montadoras americanas. A primeira empresa certificada no mundo foi a Delphi Saginaw Steering Systems dos EUA (Chowdhury e Zimmer, 1996), enquanto que na América Latina foi a Meritor do Brasil - Divisão LVS - antiga Rockwell Fumagalli, em 1995 (Miguel, 1998). Desde então, diversas empresas vêm obtendo a certificação. Até fevereiro de 1999, existiam 88 certificados emitidos no Brasil (NBS, 1999). Nesse contexto, esse trabalho enfoca a implantação da QS 9000 em uma empresa fabricante de freios automotivos na região de Campinas. O trabalho descreve, suscintamente, a evolução no desenvolvimento da QS 9000, com o 
conteúdo resumido de suas edições, destacando as alterações que vigoram na sua última versão (QS 9000, 1998). Também apresenta outros casos de implantação extraídos da literatura, destacando, finalmente, os resultados do estudo realizado.

\section{A QS 9000}

Em 1992, as três maiores montadoras dos EUA Chrysler, Ford e GM - juntamente com alguns fabricantes de caminhões se unem visando a unificação de seus sistemas da qualidade, buscando maiores exigências em relação às normas da série ISO 9000 e lançam, em agosto de 1994 a primeira versão da QS 9000, com a primeira revisão em fevereiro de 1995, incorporando mudanças recomendadas pelas afiliadas das Big Three na Europa. Na verdade, o lançamento da QS 9000 foi devido pelo fato de que não havia tempo para se esperar que as revisões das normas da série ISO 9000 chegassem ao nível exigido por esse segmento, uma vez que estas são generalistas, enquanto que os requisitos da QS 9000 são deterministas ${ }^{l}$ (Barrela, 1997). A QS 9000 foi dividida em três seções, onde a primeira enfoca os 20 elementos da ISO 9001, colocando requisitos adicionais em 18 deles. A segunda seção englobava requisitos de sistematização do desenvolvimento de produtos através do "Advanced Product Quality Planning APQP" e o "Production Parts Approval Process - PPAP", requisitos de gerenciamento de um processo de melhoria contínua através do monitoramento de indicadores, buscando reduzir os custos de produção, e enfocando também a avaliação da capacidade dos processos de manufatura. A terceira seção, apresenta os requisitos específicos das montadoras. A versão válida desde janeiro de 1999 é a terceira edição (QS 9000, 1998), lançada em março de 1998, trazendo as seguintes mudanças em relação à edição anterior:

- A Seção II, Requisitos Específicos do Setor, foi incorporada na Seção I - Requisitos Baseados na ISO 9000;

- As Interpretações Sancionadas foram incluídas na sua

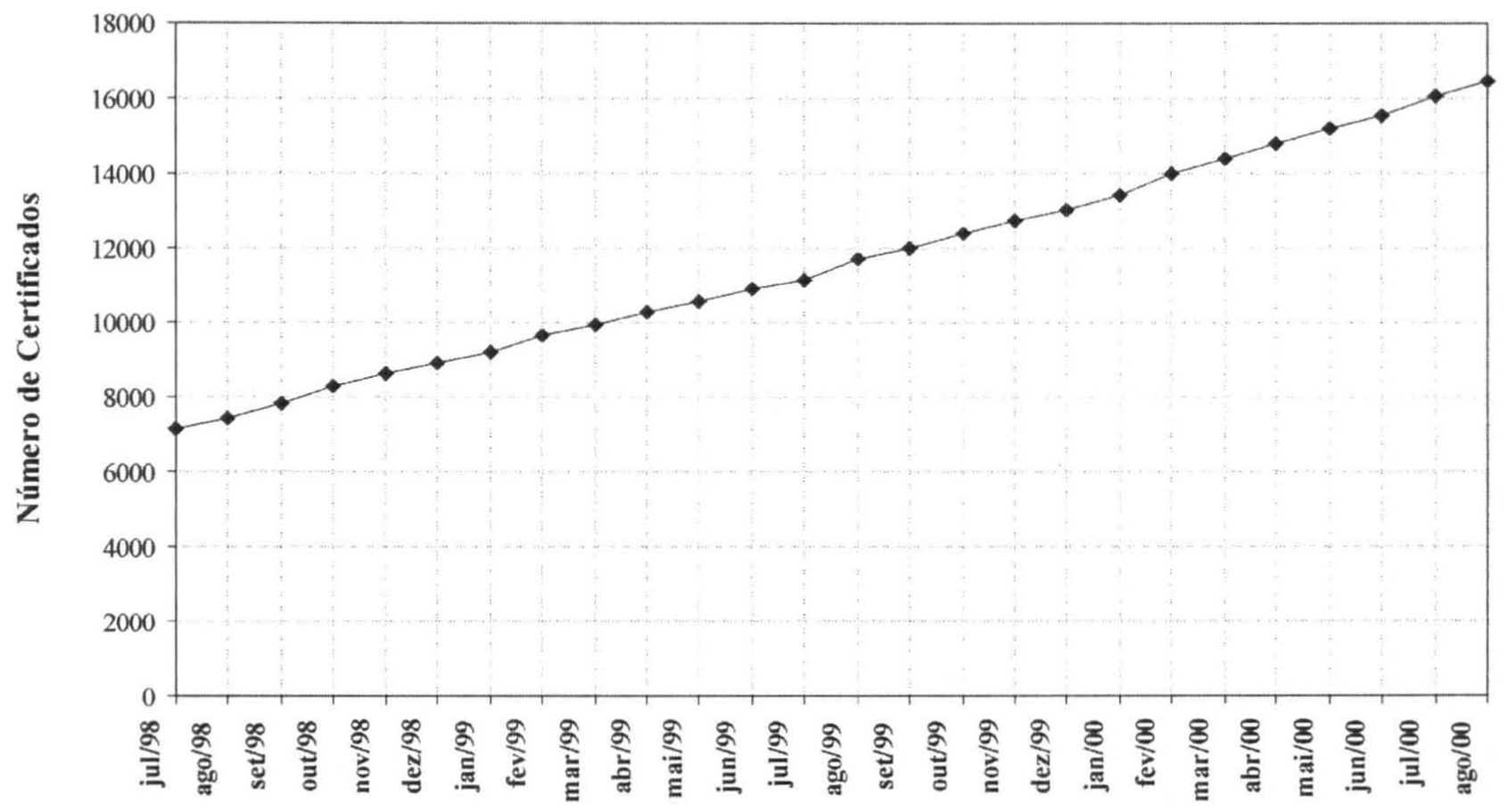

Fig. 1 - Evolução na Certificação QS 9000 no Mundo (Fonte: www.asq.org).

\footnotetext{
1 Nota dos autores: o termo "determinista", nesse caso, não é aplicado na sua forma usual da terminologia técnica tradicional, como por exemplo, similarmente a "estocástico" ou "probabilístico". O uso do termo da maneira colocada, objetiva ilustrar o carater "determinador", "pré-determinado", ou específico ao segmento automotivo.
} 
maioria como notas nos diversos requisitos;

- A palavra deveria de uma abordagem preferencial passa a ser um requisito obrigatório com alguma flexibilidade tolerada dependendo da metodologia;

- fornecedor deve notificar o orgão certificador por escrito num prazo de cinco dias úteis, quando um cliente coloca a planta do fornecedor nas situações de "Necessita de Melhoria" da Chrysler, "Revogação" da Ford e "Contenção Nível II" da GM;

- Foi reforçado o requisito de Gerenciamento das Instalações e Ferramental, anteriormente na Seção II da segunda edição e agora no item 4.2 .6 da Seção I;

- Foi incluída a cláusula de "Confidencialidade" no item 4.4 - Controle de Projetos;

- Foram incluídos no item 4.10 de Inspeção e Ensaios, requisitos adicionais para o Laboratório de Fornecedores e Laboratórios Credenciados, direcionando às práticas de administração dos laboratórios da empresa, e de qualificação dos laboratórios de terceiros utilizados pelo fornecedor;

- Foram incluídos serviços de calibração do item 4.11 Controle de Equipamentos de Inspeção, Medição e Ensaios;

- Foi acrescentada a utilização de ações corretivas para eliminar causas de não-conformidade em processos $e$ produtos similares;

- Foi incluído o requisito de Comunicação Eletrônica no item 4.15.6 - Entrega.
Existem ainda diversos de manuais que faze parte da série QS 9000, que incluem metodologias mais detalhadas onde a norma se propõe atuar: $A P Q P$ Advanced Product Quality Planning (Planejamento Avançado da Qualidade do Produto), PPAP - Production Parts Approval Process (Processo de Aprovação de Peças de Produção), MSA - Measure Systems Analysis (Análise de Sistemas de Medição), SPC - Statistical Process Control (CEP - Controle Estatístico do Processo), FMEA -

Failure Mode and Effects Analysis (Análise dos Modos de Falhas e seus Efeitos), e QSA - Quality System Assessment (Avaliação do Sistema da Qualidade). O fluxo de processo da Figura 2 mostra a relação entre os requisitos normativos no processo de adequação à QS 9000.

\section{QS 9000 - ALGUNS CASOS DE IMPLANTAÇÃO}

Conforme citado anteriormente, a Meritor do Brasil Divisão LVS, antiga Rockwell-Fumagalli, foi a primeira empresa a receber o certificado QS 9000 no Brasil e na América Latina (Miguel, 1998). A empresa é fabricante de rodas de aço, sediada na cidade de Limeira no estado de São Paulo, possuindo 44 plantas em 15 Países, tendo como principais clientes no Brasil a Fiat, Ford, General Motors, Volkswagen, Toyota e Honda. Como primeira empresa certificada na América Latina serviu como benchmark para muitas outras. Para sua adequação teve como ações principais (Costa, 1997):

- Tornar o Plano de Negócios um documento controlado;

- Comparar com os concorrentes a satisfação do cliente;

- Implantação do APQP em times departamentais;

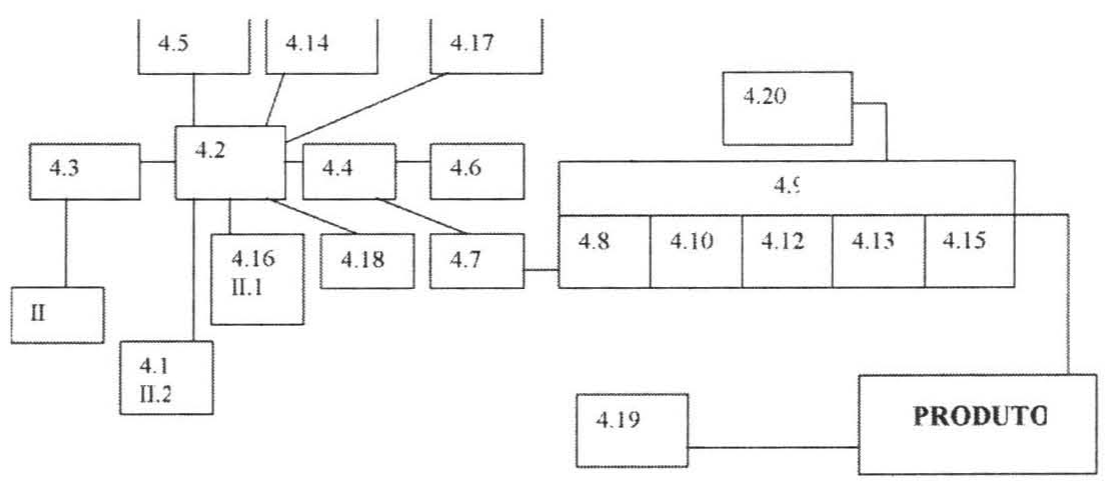

Fig. 2 - QS 9000 - Fluxo de Processo e Relacionamentos. 
- Buscar habilidades requeridas na Engenharia do Projeto (FMEA, QFD, DOE etc.);

- Identificar as características especiais nos documentos;

- Determinar as características especiais de processos nos planos de controle com seus respectivos planos de reação;

- Estabelecer uma manutenção preventiva com estoque de componentes para reposição;

- Estabelecer estudos de MSA (Análise de Sistemas de Medição) e $R \mathcal{E} R$ (Repetitividade e Reprodutibilidade) nas atividades da metrologia;

- Utilizar a Metodologia de Análise e Resolução de Problemas em Equipe "8D", entre outros.

A quarta empresa no Brasil a receber a certificação $Q S$ 9000 foi a Freios Varga S.A., fundada em 1945, fabricante de sistemas de freio para empresas como Chrysler, Ford, General Motors, VW e outras montadoras automotivas. Conforme Bueno (1997), a empresa foi certificada pela ISO 9001 em 1992 (planta de Engenheiro Coelho), em 1994 (unidade de compressores), e em 1996 (áreas restantes da unidade de Limeira, SP). Na sua preparação para a adequação à QS 9000, foram formados times com autonomia para cumprimento de um cronograma estabelecido. Cada departamento da empresa indicou um de seus membros para coordenar as ações relativas ao departamento na adequação a essa norma, realizando as seguintes atividades: levantamento das necessidades, provisão de recursos para execução, tomada de decisões $e$ apontamento de diretrizes, solução de problemas, participação em reuniões de resultados, priorização de atividades, e auditorias do andamento do trabalho de sua responsabilidade.

Tendo a implantação da QS 9000 focada na educação $e$ treinamento, a empresa investiu US\$ $15.000 \mathrm{~cm}$ treinamento, chegando a marca de 204 horas-homem/ ano (1996). A implantação foi iniciada em março de 1996. Em agosto, numa auditoria interna foram detectadas 128 não-conformidades. Na pré-auditoria, em dezembro de 1996, foram levantadas 53 nãoconformidades, sendo $25 \%$ destas sistêmicas, e $75 \%$ operacionais, as quais através de planos de ação corretiva foram fechadas em fevereiro de 1997, culminando com a certificação em março de 1997 (Calarge et al., 1997).

Todo esse processo encontrou dificuldades devido ao início do processo de certificação QS 9000 no Brasil.
Outras dificuldades encontradas foram: a implantação do CEP, a elaboração de revisões de PPAP e atualizações dos roteiros de fabricação (planos de trabalho).

A USIMINAS foi outra empresa precursora na certificação QS 9000 no Brasil. Empresa do ramo siderúrgico, foi certificada pela ISO 9001 em 1992, obteve a certificação QS 9000 em novembro de 1996. Com requisitos submetidos a interpretações particulares de uma indústria siderúrgica, produtora de aços laminados planos, buscou-se adequar os requisitos a este segmento industrial (Mitkiewicz et al., 1997). Na designação de características especiais, apesar dos clientes não as terem formalizado, a USIMINAS considerou a composição química, a largura, a espessura, a planeza, a rugosidade superficial e as propriedades mecânicas como características especiais para os principais processos. No requisito de desempenho para processos em andamento, verifica-se que este é definido pelo cliente. A utilização do controle estatístico do processo nas suas principais linhas de produção, é substituido pelo controle do processo via computador que utiliza modelos matemáticos para corrigir em tempo real as variações existentes em torno dos valores visados. Cálculos de capabilidade (capacidade do processo) são realizados para características especiais definidas nos planos de controle, a partir de dados armazenados no sistema informatizado. No requisito itens de aparência, os produtos laminados planos só se enquadram nessa situação após estampagem, a qual é executada pelo cliente. Como resultados finais, foi difícil quantificar os benefícios exclusivos que a implementação dos requisitos da QS 9000 trouxeram à empresa (Mitkiewicz et al., 1997). Alguns resultados provenientes da implantação dessa norma foram reconhecidos, como por exemplo, um sistema de determinação da satisfação dos clientes que permitiu identificar as suas necessidades de maneira objetiva, permitindo uma tomada de ação direcionada à melhoria no atendimento destas necessidades. $\mathrm{Na}$ adoção dos cálculos de capabilidade de processos para características especiais, aprimorou-se o conhecimento dos pontos fortes e limitações das instalações da empresa através de indicadores numéricos para futuras tomadas de decisões. Quanto à confiabilidade dos resultados, buscou-se o credenciamento do laboratório de ensaios mecânicos e metalográficos junto à Rede Brasileira de Calibração $R B C$, e foram exigidos o conhecimento e o uso de toda a metodologia de estudos estatísticos referenciados pelo 
manual MSA da QS 9000. Com a certificação QS 9000, a USIMINAS passou a constar da lista de fornecedores mundiais (Global Source) da Ford, General Motors e Chrysler, abrindo maiores mercados e adequando a empresa para uma competitividade mundial (Mitkiewicz et al., 1997).

A Companhia Siderúrgica Paulista - COSIPA - foi outra empresa do ramo siderúrgico a buscar a certificação $Q S$ 9000 (Oliveira et al., 1998). Nessa empresa, teve-se a necessidade de uma minuciosa análise para traduzir os requisitos dessa norma ao setor siderúrgico, com uma intensa troca de informações com as montadoras automotivas. Certificada ISO $9001 \mathrm{em}$ outubro de 1995 nos produtos da linha de chapas grossas, tiras a quente $e$ tiras a frio, a COSIPA buscou uma nova certificação internacional, denominada "Selo JIS", concedida pelo governo japonês às empresas onde se aplicam o controle estatístico da qualidade de forma eficaz e a sistemática de garantia da qualidade, visando atender as necessidades do cliente. Confrontando os requisitos do JIS e os da QS 9000, constatou-se pontos essenciais semelhantes. Tendo considerado a QS 9000 vaga na definição das características especiais, tomou-se como base a JIS, que aborda de forma mais conclusiva o produto siderúrgico, definindo as características do produto como sendo aquelas que serão objetos de estudos estatísticos e a estrutura de documentos necessária à sua implementação no chão de fábrica. Seguindo esse modelo japonês, foi elaborada a Norma de Gerenciamento do Produto (NPC) para aços estruturais, originando novas NPCs para aplicação no setor automotivo, implementando orientações do manual do APQP, elemento fundamental na adequação à QS 9000. A equipe do sistema da qualidade após um minucioso estudo da QS 9000 e seus manuais complementares (CEP, PPAP, MSA, FMEA, APQP e $Q S A)$, elaborou o documento "Diretrizes Operacionais para Certificação QS 9000", traduzindo os requisitos dessa norma à realidade da empresa, sendo um documento utilizado para treinamento da equipe de certificação e como check-list de auditorias internas. Esse documento incluiu prazos e responsáveis para a implementação de cada requisito. Uma equipe multidisciplinar com 30 colaboradores foi criada a fim de analisar, otimizar e viabilizar o documento com as diretrizes operacionais. Desde o início dos estudos sobre a QS 9000 em outubro de 1996, passando pela préauditoria em maio de 1997, planos de correção dos desvios detectados foram implementados, culminando na certificação em setembro de 1997(Oliveira et al., 1998).

Constando da lista de empresas pioneiras na implantação da QS 9000 no Brasil, está a planta da Fundição Ford do Brasil Ltda., situada em Osasco (Hechert $e$ Chaves, 1997). Como uma subdivisão da Ford do Brasil, a Fundição Osasco conta com 441 funcionários empregados na produção de componentes de chassis de caminhões das séries " $F$ " $e$ "Cargo" e peças para motores como virabrequins, cubos de roda, suportes de mola, entre outras, tendo como principais clientes as plantas da Ford de São Paulo e Taubaté, a Volkswagen do Brasil e a Bosch Freios. A adequação à QS 9000 se deu como parte da política da qualidade Ford, que é difundida pela matriz dos EUA $e$ desenvolvida por todas as unidades no mundo. $\mathrm{Na}$ evolução do seu sistema da qualidade, a Ford Osasco, iniciou seu processo pela implantação do processo originado no Q1 (padrão de sistema da qualidade Ford), evoluindo para o padrão ISO 9000 e culminando com a certificação QS $9000 \mathrm{em}$ outubro de 1996. Já possuindo a ISO 9002 desde agosto de 1995, a empresa partiu para a adequação aos requisitos adicionais da QS 9000, como por exemplo, ao evidenciar a filosofia de melhoria contínua conduzida através dos planos de ação, contemplando ao mesmo tempo propostas para melhoria contínua dos processos. Reconhecendo como essencial a participação de todos os funcionários, a empresa valoriza o trabalho em equipes multifuncionais e através do programa "Integração Organizacional", informa mensalmente a todos os empregados a evolução de seus objetivos promovendo o comprometimento de todos. Como benefício da implantação da QS 9000, destacou-se a padronização dos processos através dos set-ups das operações e procedimentos internos da qualidade e folhas de instruções, melhorados a partir da ISO 9000, expressa nas melhorias mostradas nos indicadores de produtividade $e$ qualidade, satisfação dos clientes com os produtos e serviços oferecidos e desenvolvimento de parceria com os seus fornecedores (Hechert e Chaves, 1997).

\section{ESTUDO DE CASO DE IMPLANTAÇÃO DA QS 9000}

A WABCO Freios Brasil é fabricante de componentes para sistema de freios a ar para veículos pesados, tendo como principais clientes as montadoras automotivas Mercedes Benz, Volvo, Ford, General Motors, Volkswagen, Scânia, entre outras. Trabalha num sistema 
de manufatura celular, com um quadro de 320 funcionários, situada na cidade de Sumaré no Estado de São Paulo. A empresa foi fundada no final do século passado pelo engenheiro George Westinghouse, que após presenciar um acidente ferroviário passou a estudar uma nova sistemática de frenagem para esse tipo de transporte. A WABCO, cuja sigla significa Westinghouse Air Brake Company, pertence ao grupo americano American Standard, detentora no Brasil de empresas em outros segmentos como a TRANE Ar Condicionados Centrais e a Ideal Standard Louças e Metais Sanitários; possui sua central tecnológica na cidade de Bruxelas na Bélgica, e tem seus principais centros de desenvolvimento tecnológico nas unidades da Alemanha, França e Inglaterra, contando ainda com unidades fabris espalhadas pelo mundo, incluindo-se Holanda, África do Sul e joint ventures com a Meritor $e$ com a Cummin's nos EUA.

A WABCO Brasil que teve o seu sistema da qualidade certificado ISO 9002 em outubro de 1995 pelo organismo certificador Lloyd's Register Quality Assurance, buscou para a adequação à QS 9000, como já havia acontecido para a ISO 9000, a formação de uma equipe interna multifuncional de implantação, coordenada por um funcionário da Engenharia da Qualidade. Através de reuniões semanais definiram-se tarefas com prazos $e$ responsabilidades para o cumprimento dos itens normativos, como também discussão pela equipe, de alternativas para os diversos assuntos tratados.

Buscando qualificar o seu pessoal nas diversas metodologias impostas, tomaram-se como tarefas iniciais a disseminação da norma QS 9000 através de um treinamento interno para todo o grupo de implantação, como também a disseminação de uma metodologia para análise e resolução de problemas para todos os setores administrativos e funcionários chaves dos setores produtivos, tendo sido escolhida a sistemática recomendada pela Ford, denominada " $8 D$ - Oito Disciplinas para Análise e Solução de Problemas em Equipe". Essa metodologia direcionou toda a organização, para casos de problemas com dificuldade de resolução, a formar equipes multidisciplinares a fim de se buscar as melhores soluções possivveis, através do conhecimento de cada membro do grupo. Por tratar-se de um requisito normativo e atuando como um facilitador nas dificuldades deparadas na implantação, essa metodologia foi de fundamental importância no processo de adequação aos requisitos da QS 9000.
Na seqüencia do processo de qualificação, partiu-se para um treinamento em APQP - Planejamento Avançado da Qualidade do Produto -, que é a estrutura dorsal da implantação da QS 9000. Fundamentado no desenvolvimento do $A P Q P$, foram sendo definidos pela equipe, treinamentos tais como FMEA - Análise dos Modos de Falha e seus Efeitos, MSA - Análise do Sistema de Medição, GDEST - Tolerância Geométrica e Dimensional, POKA YOKE - Metodologia a Prova de Erros, e Técnicas de Melhoria Contínua, sendo estes ministrados por consultorias externas. Também foram determinados treinamentos de reciclagem em metodologias já em uso como MPT - Manutenção Produtiva Total - e CEP - Controle Estatístico de Processo -para operadores e engenheiros.

A WABCO tem sua estrutura organizacional delineada a partir dos processos existentes na empresa. Este delineamento deu-se em $1995 \mathrm{com}$ a implantação em nível organizacional, para todas as empresas do grupo da American Standard, do programa DFT - Demand Flow Technology (Tecnologia do Fluxo através da Demanda) -, resultando nas gerências de: Fabricação $e$ Sistemas da Qualidade, que engloba a Engenharia Industrial, Engenharia de Produção, Engenharia da Qualidade, Manutenção e Ferramentaria; Logística, que engloba o Planejamento de Produção, Expedição, Recebimento e Compras; Engenharia de Desenvolvimento, que engloba a Engenharia do Produto, Engenharia de Aplicação, Vendas e Assistência Técnica; Financeiro, que engloba a Controladoria, Custos $e$ Informática; e Recursos Humanos, que engloba Segurança Industrial e Patrimonial, Restaurante, Treinamento e Pessoal. Para estas cinco áreas foram dadas diretrizes, sempre através de seus representantes na equipe da QS 9000, com algumas diretrizes descritas a seguir:

- Na Engenharia de Fabricação direcionou-se responsabilidade efetiva nos FMEAs de processo, instruções para o set-up de máquinas, acompanhamento de ferramentais perecíveis, aprimoramento no sistema de manutenção produtiva total, gerenciamento de ferramentais internos e dos alocados em fornecedores, aprimoramento do sistema Kanban e formalização do processo de melhoria contínua realizado nas equipes multidisciplinares de análise das células de manufatura.

- Na Logística direcionou-se maior sistematização do processo visando garantir o atendimento em $100 \%$ da perfomance de entrega de fornecedores como também 
clientes, gerenciamento dos estoques em função das metas existentes.

- Na Engenharia de Desenvolvimento direcionou-se a adequação ao requisito "4.4 - Controle de Projeto" devido a WABCO buscar um up-grade de ISO 9002 para ISO 9001. Na certificação QS 9000, foi considerada a estruturação do $A P Q P$ pela equipe de desenvolvimento de novos produtos, levantamento da satisfação do cliente final (transportadoras que utilizam-se de veículos com produto WABCO), e a responsabilidade pelos FMEAs de Projeto.

- No setor de Recursos Humanos direcionou-se: melhorias no sistema de levantamento das necessidades de treinamento e avaliação da sua eficácia, estudos ergométricos na empresa, revisão do mapa de risco da empresa, melhoria na definição das áreas com necessidade de uso de EPIs - Equipamentos de Proteção Individual.

- No Financeiro direcionou-se: responsabilidade para atuar como facilitador na disponibilização de recursos de informática necessários para os diversos setores, $e$ auxílio na elaboração dos indicadores para o Sistema Operacional da Qualidade.

Em setembro de 1998 foi disseminado a todos os funcionários da empresa o livreto WABCO - QS 9000 em treinamentos de quarenta e cinco minutos de duração, ministrados por engenheiros e técnicos da Engenharia da Qualidade. Programas de auditorias internas foram intensificados, formal e informalmente, pelo corpo de auditores internos, os quais são todos qualificados externamente como Lead Assessor, atualmente Lead Auditor, pela MCG - PE Batlas (organismo britânico responsável pelo credenciamento de auditores em nível internacional) e onde foram continuamente levantados pontos de melhoria, tendo inicialmente como diretriz cobrir completamente os requisitos normativos, deixando simplificações para uma segunda etapa.

\section{- 4.2.1 Resultados Obtidos com a Certificação}

Adequando-se à QS 9000 a WABCO estruturou o seu sistema da qualidade com a utilização das metodologias exigidas e, vem continuamente buscando aprimorá-las na finalidade de um real agregamento de valor ao sistema produtivo. No atual ambiente mundial, somente alcança-se a competitividade com uma redução dos custos de produção, e através da correta utilização das diversas metodologias existentes, é que se possibilita atingir a meta de redução de custos.

Visando essa redução de custos e uma adequação aos padrões internacionais, com informações da estratégia global da organização, o ambiente atual, benchmarking com outras organizações, expectativas dos clientes e a própria missão da empresa, é formulado o planejamento estratégico da empresa onde são desdobrados indicadores nos diversos níveis hierárquicos, desde o Diretor Presidente até o chão de fábrica. A esses indicadores são atribuídos "donos", os quais são os responsáveis por atingir as metas, pela tomada de ações direcionadas às metas, pela verificação da eficácia dessas ações, por cobrar ações em indicadores de nível inferior ao em questão, e por reportar os resultados encontrados nos indicadores estabelecidos para cada categoria. Como exemplo dessa sistemática, tem-se que o indicador de Custos da Não-qualidade alimenta o indicador de Custo Total da Qualidade, e é alimentado pelos Índices de Refugo, Retrabalho, Devolução e Garantia.

A Figura 3 apresenta os índices de rejeição nas bancadas de teste das linhas de montagem. Todos os produtos WABCO são testados $100 \%$ em linhas de montagem. Verifica-se o acompanhamento dos percentuais de defeituosos desde o ano de 1982 até 1999. Verifica-se o acompanhamento do percentual de defeituosos encontrados nas bancadas de teste em três fases distintas:

a) Anterior ao fechamento da área de montagem $e$ transferência da responsabilidade dos testes para a produção (final de 1997);

b) Após o fechamento da área de montagem e transferência da responsabilidade dos testes para a produção até o início do programa Just-in-Time/TQC -Total Quality Control (entre o final de 1997 e o início de 1991);

c) Após o início do programa Just-in-Time /TQC (a partir do início de 1991).

O acompanhamento do percentual de defeituosos no ano de 1999, foi feito a partir de uma meta pré estabelecida de 2,5\% dos produtos testados. Até meados de 1999, o índice esteve, em média, acima dessa meta $(3,6 \%)$. A partir de agosto esse valor foi reduzido para $2,1 \%$, portanto, abaixo da média. $O$ direcionamento dos 
esforços através do acompanhamento das irregularidades nos relatórios de rejeição de bancadas de teste, com a elaboração de gráficos de Pareto e tomada de ações nas principais falhas, vêm propiciando uma tendência ao atendimento da meta estabelecida. Isso acontece pela atuação de equipes multifuncionais para resolução de problemas, baseadas nos levantamentos mensais das falhas mais significativas.

A Figura 4 mostra a evolução na melhoria dos produtos da empresa em partes por milhão ao longo do tempo. Na figura, são acompanhados os índices de devolução de produtos (peças retidas na inspeção do recebimento da montadora) e garantia (irregularidade detectada no campo), desde 1982. O fechamento de 1998 foi com 521 ppm de Garantia e 199 ppm de Devolução de Cliente. Estes indices foram considerados adequados, pois foi atendida a meta de devolução $e$, apesar do nãoatendimento da meta de garantia para a própria empresa, esta atingiu um índice próximo a meta de algumas montadoras, como por exemplo a Mercedes Benz, que tem como meta o índice de 500 ppm. No ano de 1999, a empresa deparou-se com irregularidades de troca dos itens fornecidos, provocadas por similaridades das peças, comprometendo os índices para o resto do ano. Estas falhas foram tratadas junto à montadora com a formação de uma equipe para resolução de problemas, com elementos da empresa e da montadora em questão, culminando com a eliminação da falha ocorrida. Mesmo tendo comprometido o índice no acumulado do ano,

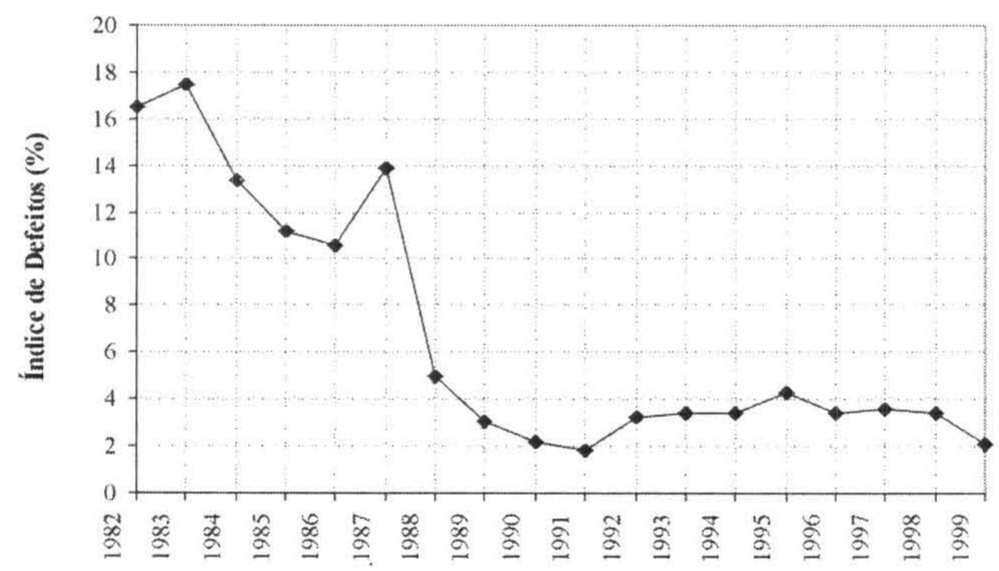

Fig. 3 - Índice de Rejeição nas Bancadas de Teste de Produtos.

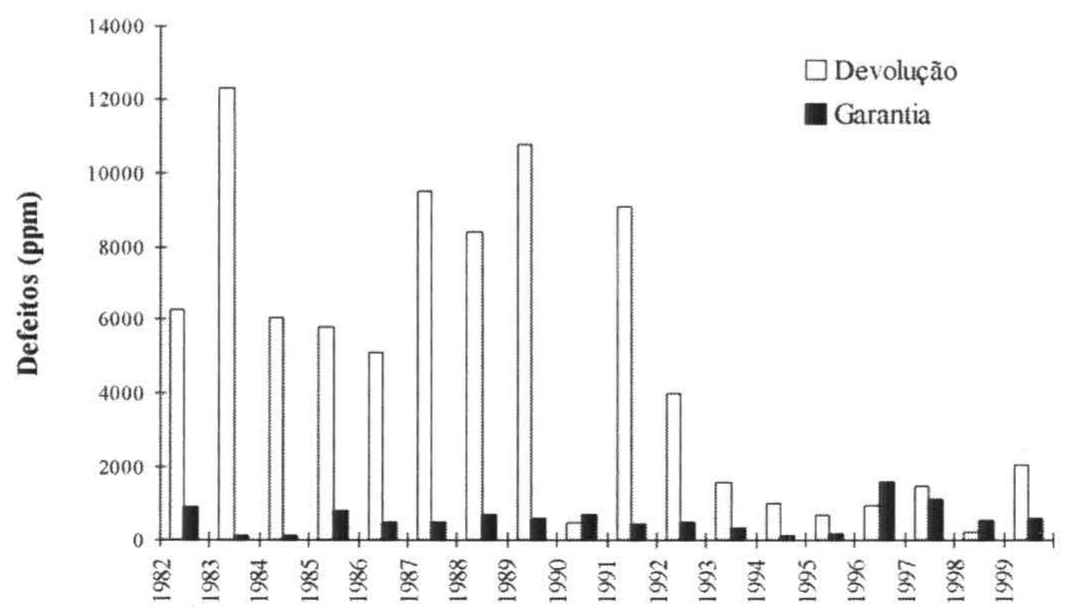

Fig. 4 - Índice de Devolução de Produtos e Garantia nas Montadoras. 
diversas ações estão sendo tomadas para a não-ocorrência de novas falhas, como por exemplo a introdução de dispositivos à prova de erros, em fases da produção responsáveis por falhas potenciais, visando uma redução significativa para o indicador até o final do ano.

Os gráficos das Figuras 3 e 4 são atualizados mensalmente e são afixados nas áreas de entrada da produção, funcionando como um retrato para os funcionários, clientes e fornecedores, da situação da qualidade da empresa ao longo do tempo, funcionando como histórico, indicando as tendências evidenciadas nas suas diversas etapas. Nos indicadores estratégicos são definidos metas, prazos e responsabilidades para o seu atendimento, sendo que o responsável (champion), ou seja, é ele quem responde pela sua performance, formando equipes multifuncionais para resolução de problemas que possam estar impactando na deterioração do indicador, como também direcionar todos os recursos disponíveis para a sua melhoria.

Tomando-se como exemplo o índice de retrabalho (Figura 5) na parte frontal do relatório, tem-se um fluxograma que o posiciona na cadeia originária dos indicadores estratégicos de primeiro nível (lado esquerdo da Figura 5), e um gráfico que mostra a tendência desse índice em relação à sua meta (lado direito da Figura 5). Além desses gráficos, existe outro (não mostrado na Figura 5), indicando o atendimento percentual em relação ao planejado (\% de atendimento à meta), e um resumo de ações tomadas através de planos de melhoria ou relatórios " $8 D$ " de análise e solução de problemas em equipe. No verso do relatório ou ainda como anexo, incluí-se um Diagrama de Pareto que prioriza as principais irregularidades para uma posterior tomada de ações. Por último, tem-se o Paynter Chart, planilha utilizada pela Ford, onde são descritas as principais irregularidades apontadas no Pareto, quantificadas e acompanhadas ao longo do tempo. Ações de contenção, corretivas e preventivas são apontadas nessa planilha através de simbologia apropriada, nas colunas relativas ao posicionamento cronológico e nas linhas das respectivas irregularidades. Com essa simbologia, através de rápida análise do Paynter Chart, é possivel visualizar imediatamente, através dos números mostrados e das sinalizações das ações tomadas, a eficácia dessas ações, as quais são verificadas nas tendências posteriores a elas.Nas Figuras 6, e 7 têmse, respectivamente, os índices para Retrabalho e Refugo, os quais alimentam o indicador de Custos da NãoQualidade. Os indicadores dessas figuras seguem o mesmo esquema relatado anteriormente. A situação do verso ou anexo é diversificada conforme o surgimento de novas irregularidades que propiciem a abertura de novos Gráficos de Pareto para priorização das novas falhas e conseqüentemente novos Paynter Charts para o seu acompanhamento.

No indicador do Retrabalho da Figura 5, verifica-se um atendimento à meta, com exceção ao mês de fevereiro, que tratou-se de uma falha devido a alterações do produto. Com a permanência dessa performance, a meta deverá ser alterada para o próximo ano.
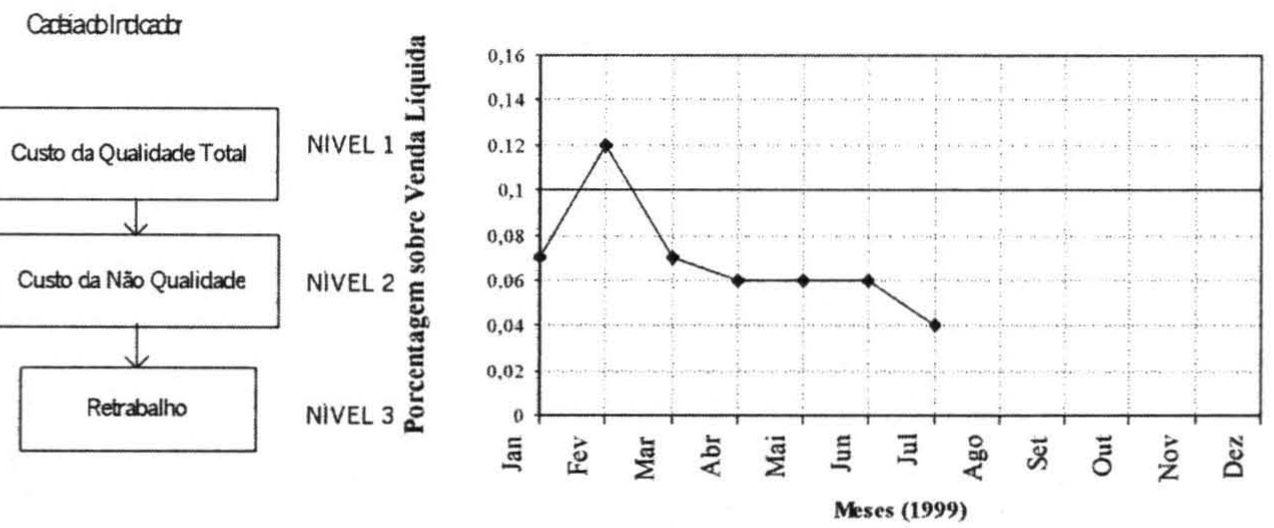

Fig. 5 - Índices de Retrabalho. 
Catiacbirdicato
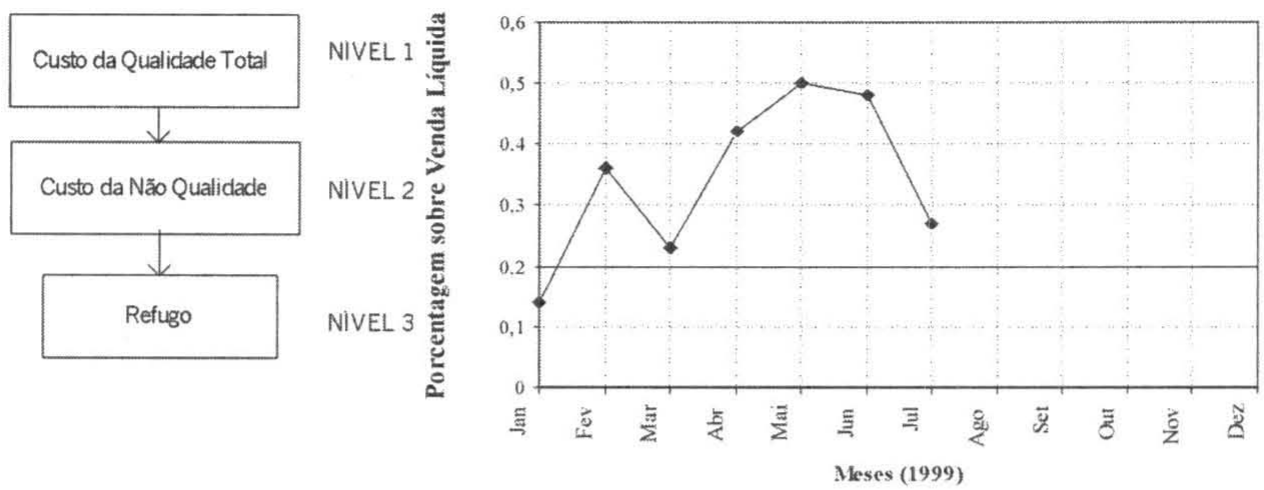

Fig. 6 - Índices de Refugo.

\section{Cattiacblrdcata}
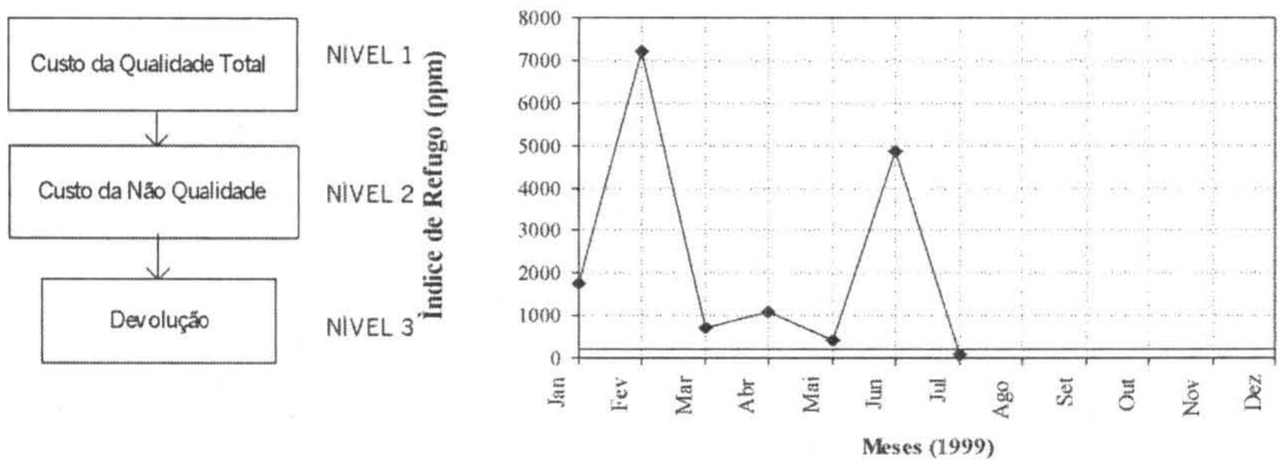

Fig. 7 - Índices de Devolução de Produtos.

No indicador de Refugo (Figura 6) são verificados índices acima da meta, sendo a maior parte destes, oriundos de problemas de porosidade em peças de alumínio. Por tratar-se de falha inerente ao processo de fundição de alumínio, está-se tomando providências quanto a um melhor processo de impregnação destas peças, trocando-se o processo atual de impregnação por silicato para uma impregnação com resina Loctite.

No caso do índice de Devolução (Figura 7) verifica-se acréscimos significativos de ppm no inicío do ano, o que mostra que a implantação da QS 9000 não conseguiu evitar a ocorrência de irregularidades, mas direcionou a tomada de ações de maneira mais efetiva. Nesse caso, abriu-se um relatório para análise de soluções de problemas na equipe multifuncional, e incluiu-se um elemento do cliente, no caso a Mercedes Benz, que ajudou no fechamento da irregularidade com a confecção de um dispositivo à prova de erros.

A partir dos indices apresentados, tem-se uma abordagem das principais irregularidades existentes, sendo que estas estarão sendo tratadas em relatórios existentes de rejeição em bancadas de teste, no caso do retrabalho, em planos de melhoria nos índices de refugos e em relatórios de não-conformidades para o caso de devoluções e garantia. $O$ que pode ser notado nos índices das figuras anteriores, é que estes não mostram os planos de melhoria ou relatórios para resolução de problemas. Nestes casos particulares isso realmente não acontece, devido a estarem mencionados em planilhas de meses anteriores. Com estes e os demais 
indicadores oriundos da estratégia da empresa, que chegam até o chão de fábrica através do seu desdobramento para as células de produção, consegue-se um gerenciamento mais eficaz de todo o processo produtivo que reflete diretamente nas metas da organização. Quando as metas não são atendidas, as ações são também desmembradas em toda a cadeia dos indicadores, unindo os esforços de forma inversa desde o chão de fábrica até a alta administração.

\section{CONCLUSÕES}

Com todos os benefícios trazidos com sua implantação, verifica-se que a certificação QS 9000 é condição necessária mas não suficiente para a sobrevivência das empresas, mesmo sendo uma metodologia de estruturação do sistema da qualidade que, desde corretamente utilizada, propicia reduções de custo e melhorias dentro da organização. Entretanto, não sobrepuja todo o contexto estratégico internacional, o qual direciona as organizações na tomada de decisões que sejam as mais apropriadas. A QS 9000 oferece através das ferramentas por ela utilizadas, oportunidades reais de melhoria e reduçöes de custo. Como verificou-se nos diversos indicadores mostrados, têm-se flutuações nos níveis de atendimento às expectativas, não tendo-se assim evidências completas de que com a implantação da QS 9000 todos esses indicadores assumiriam posições de melhoria. Porém, pode-se demonstrar sua contribuição na estruturação da organização para uma eficaz tomada de decisão para a recomposição dos indicadores estratégicos ao longo de sua cadeia. Resumindo, oter a certificação QS 9000 não é uma garantia de sucesso, mas sim de possuir uma metodologia a mais para alcançá-lo.

\section{REFERÊNCIAS BIBLIOGRÁFICAS}

ASQ - American Society for Quality. Internet: http:// www.asq.org/standcert/qs9000/compdir.html, julho, 2000.

Barrela, B. "Conceito da QS 9000". Anais do I Seminário em Qualidade: QS 9000 - Princípios, Interpretação e Implantação, Universidade Metodista de Piracicaba, Santa Bárbara d'Oeste, SP, p.4-8, setembro, 1997.

Bueno, U.S., "QS 9000 - A Experiência da Freios Varga S.A.". Anais do $1^{\circ}$ Seminário em Qualidade: QS 9000 Princípios, Interpretação e Implantação, Universidade
Metodista de Piracicaba, Santa Bárbara d'Oeste, SP, p.9-32 setembro, 1997.

Calarge, F.A., Zanini, R.A. e Lima, P.C., "QS 9000: Um estudo de caso enfocando a implantação e certificação de uma empresa do setor automotivo". CD ROM do $17^{\circ}$ Encontro Nacional de Engenharia de Produção, Gramado, RS, outubro, 1997.

Chowdhury, S., e Zimmer, K., "QS 9000 Pioneers", ASQ, Quality Press, USA, 1996.

Costa, A.B. "Implantação da QS 9000 na Rockwell-Fumagalli". Anais do $1^{\circ}$ Seminário em Qualidade: QS 9000 Princípios, Interpretação e Implantação, Universidade Metodista de Piracicaba, Santa Bárbara d'Oeste, SP, p.3350 setembro, 1997.

Hechert, C.R., Chaves, E.R., "A Implantação da QS 9000 na Fundição Osasco Ford Brasil Ltda. CD ROM do $17^{\circ}$ Encontro Nacional de Engenharia de Produção, Gramado, RS, outubro, 1997.

Miguel, P.A.C., "Brasilian Quality Nutshell", Quality World, p.38-44 novembro, 1998.

Mitkiewicz, J.W., Barbosa, A.W.Q. e Carneiro, M.A., "Aplicação dos requisitos da QS 9000 em uma indústria siderúrgica produtora de aços laminados planos". Anais do VI Seminário de Gestão pela Qualidade, Vitória, ES, p.183195, agosto, 1997.

NBS - Nacional Bureau de Serviços. Internet: www.nbs.br, março, 1999.

Oliveira, V.P., Machado Jr., A.J. e Moreira Filho, U.M., "Implantação da QS 9000 na COSIPA". Anais do VII Seminário de Gestäo pela Qualidade, Belo Horizonte, MG, p.111-119, agosto, 1998. 